\title{
BASICALLY DESERVED BLAME AND ITS VALUE
}

\author{
Michael McKenna
}

$\rrbracket]$ OW SHOULD WE understand basic desert as a justification for blaming? Many philosophers account for free will by identifying it with the control condition for basic desert-entailing moral responsibility. ${ }^{1}$ On such a view, a blameworthy person deserves blame just because of how she acted-for instance, because she knowingly and freely acted morally wrong. Crucially, the justification provided by desert is not rooted in any other normative consideration, such as utility, or the reasonableness of entering into a contract with others. ${ }^{2}$ But what precisely does basic desert come to? And what is it about blame that makes it the thing that a blameworthy person deserves? Moreover, how is any particular instance of blame fitted properly - rather than ill fitted-for a blameworthy person's particular act so that it is the thing that is deserved? As it turns out, there are challenges to understanding basic desert for blame, challenges having nothing to do with skepticism about free will. One challenge concerns whether the only good in harming a person by blaming her is exclusively instrumental. Another challenge concerns traditional worries about retributivist theories of punishment that might threaten deserved blame too. Given these challenges, there may be reason to reject desert-based conceptions of the justification of blame for reasons altogether distinct from any worries about free will.

In what follows, by drawing upon my own conversational theory of moral responsibility, I will develop the view that blame is to be justified in terms of basic desert. ${ }^{3}$ I have three interrelated aims. One is to account for the fittingness of blame on analogy with the fittingness of a move in an actual conversation between competent linguistic practitioners of the same language. Another is to solve the problem of explicating the desert relation regarding what is deserved by the blameworthy in a way that helps avoid traditional worries about retributive

1 E.g., Fischer and Ravizza, Responsibility and Control; Mele, Free Will and Luck; Pereboom, Free Will, Agency, and Meaning in Life; and Sartorio, Causation and Free Will.

2 E.g., Feinberg, Doing and Deserving; Pereboom, Living Without Free Will and Free Will, Agency, and Meaning in Life; and Scanlon, Moral Dimensions.

3 McKenna, Conversation and Responsibility. 
theories of punishment. The third is to defend the controversial thesis that the harm involved in blaming can be good in a way that is not merely instrumental.

In developing this view, I mean to articulate an account of basic desert-entailing moral responsibility that is neutral between freewill realists and freewill skeptics. This should prove useful in helping adjudicate the debate between those realists and skeptics who agree that what is in dispute between them is the freedom required to deserve blame in a basic sense. I will restrict myself just to blameworthiness and blame, leaving aside praiseworthiness and praise, as well as moral responsibility for conduct that is neither praiseworthy nor blameworthy.

I begin with two preliminary qualifications. First, the instances of blame I take to be of interest, and the role basic desert plays in justifying them, have to do with directed blame, wherein those blaming direct their blame toward the blamed person by overt means. ${ }^{4}$ In such cases, the blamed person is positioned to recognize the blame and register that those blaming her intend that she receive their blame. Second, I assume that, at least in paradigmatic cases, directed blame harms the person blamed. For this reason, I will assume that one cannot justify the goodness in blaming a person unless one can also justify the harms that attend blame. ${ }^{5}$

\section{BASIC DESERT}

With the preceding clarifications in place, consider basic desert. What is it? Given what has already been stated, we know that it is basic at least in the following negative way: the normative warrant it provides is not supported by any more fundamental normative principles or values. ${ }^{6}$ But that is not saying much. What more can be said to give some positive content to our understanding of it? I will restrict my attention to deserved moral blame. I will not concern myself with

4 McKenna, "Directed Blame and Conversation."

5 I take it as a fact about the sort of blame at issue that it is liable to harm in various ways, and that the normative burden of offering a justification for blaming requires a justification for these sorts of harms. Of course, there are antiseptic notions of blame, like Smart's notion of dispraise, which are meant to be washed clean of any harmful effects ("Free-Will, Praise and Blame"). But most assume, as Pamela Hieronymi puts it, that blame directed at a blamed person has a force or a characteristic sting, something painful or burdensome ("The Force and Fairness of Blame"). Part of the philosophical project of offering a theory of moral responsibility and of justified blame requires accounting for and justifying this. I am grateful to a referee from this journal for asking me to clarify this point.

6 E.g., see Feinberg, Doing and Deserving, 56; Pereboom, Free Will, Agency, and Meaning in Life, 2; and Scanlon, Moral Dimensions, 188. 
basic desert in other domains, like the desert for winning a prize or being treated with respect as a person.

To begin, desert offers a distinctive way of specifying the sense of aptness in a judgment that blame is appropriate. ${ }^{7}$ Mere aptness on its own simply reports that some normative warrant exists; it gives no content to the kind of warrant on offer. Desert does so, not by appealing to considerations of utility, or principles of fairness, or the elements of a reasonable contract, but by appealing exclusively to a "desert-base" that makes fitting that which is deserved. ${ }^{8}$ So understood, desert is a distinctive species of fittingness. As regards deserved blame, the desert-base for a blameworthy act involves only salient features of the agent and her act, features that make the agent blameworthy for it. Suppose, to make things simple, this consists just in an agent knowingly and freely doing morally wrong. Here we have three ingredients contributing to the desert-base: one concerns the agent's state of knowledge, another concerns the agent's relation to the act as a free one, and the third concerns the moral status of the act itself as one that is morally impermissible. These features provide the desert-base for a response that is fitted for the agent's act-in particular, a blaming response.

The blaming response is meant to fit the act in relation to the features of the desert base in some unique, case-specific manner, one that is especially difficult to specify. (I offer a proposal below.) There is, furthermore, as noted above, a widely shared presumption that blaming is negative in a way that involves exposing the one blamed to the liability of certain harms; it has a characteristic sting or force. Crucially, the blame's being basically deserved exhausts the requisite positive normative warrant for exposing the blameworthy agent to such harms.

Why write in terms of basic desert exhausting the positive normative warrant for blaming? On a credible version of a basic-desert thesis, the complete normative warrant for actually blaming an agent, one yielding an all-out judgment, also requires the negative condition that there are no competing and overriding normative considerations, like those of overall utility or simple prudence, speaking against blaming. Hence, basic desert only provides pro tanto reasons. So it does not immediately follow that if it is true that a person deserves blame, in the all-out sense the right thing for someone (or other) to do is blame that person.

To help give further content to judgments of deserved blame, it is useful to consider whether they involve only the right or instead also the good. ${ }^{9}$ There is

7 Feinberg, Doing and Deserving, 56-57.

8 Feinberg, Doing and Deserving, 58-61.

9 In what follows, I will seek an elucidation of basic desert by considering whether a claim of basic desert entails a judgment that is either deontic or axiological. One referee for this journal expresses skepticism for this strategy. About the proposal I will advance in this para- 
no consensus on this point. Some have in mind an exclusively deontic rendering. For example, as Joel Feinberg put it:

That a subject deserves $X$ entails that he ought to get $X$ in the pro tanto sense of "ought." ${ }^{10}$

On such a view, there is no entailment from its being deserved to its being good that a blameworthy wrongdoer is blamed and thereby harmed. Indeed, in developing his own "desert-based view," Scanlon explicitly denies this:

The fact that someone has behaved wrongly can make it appropriate to withhold certain attitudes and relationships, and withholding these things may make the person's life worse. But withholding them is justified, in my view, by the fact that they have become inappropriate, not by the fact that withholding them makes the person worse off. Ceasing to hope that things go well for a person can be one element of blame, but as I have emphasized, this does not involve thinking it to be good that things not go well for him. ${ }^{11}$

On a strong version of an exclusively deontic desert thesis, blaming one who deserves blame would be construed as a duty or an obligation. On a weak rendering, it would be cast simply as something that is permissible. ${ }^{12}$

Others favor an axiological thesis that supplies the basis for a deontic judgment. On such a view, the goodness of the harm in blaming provides a justification for, at a minimum, the permissibility of doing so. ${ }^{13}$ In advancing such a view, Christopher Bennett writes:

graph, they write, "Put this way, the view does not appear to answer a question that [the author] raises at the start: what is basic desert? An entailment of basic desert is identified, but identifying an entailment of it is not saying what it is. Basic desert seems to be left as a something-or-other that entails this value." In response, I do not think this is quite right. While it is true that, in some cases, we do not learn what $\mathrm{x}$ is by learning what is entailed by $\mathrm{x}$. But sometimes we do. We learn something about a dolphin when we learn that it is a mammal, and so it is informative to learn that "Flipper is a dolphin" entails "Flipper is a mammal." The salient feature of my philosophical strategy is to seek some non-reductive means of elucidating desert when it is regarded as basic and so not grounded in any more basic normative notion. I am treating the entailments identified here as markers of essential features of desert wherein desert is the ground for either the rightness or goodness of the deserved thing. (I wish to emphasize here my gratitude to this referee for pressing me on this and several other matters in the following couple of paragraphs.)

Feinberg, Doing and Deserving, 60.

Scanlon, Moral Dimensions, 188.

E.g., Scanlon, Moral Dimensions, 188-89.

E.g., Bennett, "The Varieties of Retributive Experience"; and McKenna, "Directed Blame 
I shall show the extent to which our participation in the reactive attitudes [ones expressive of blaming] betrays a commitment to retribution, to the thought that it is a non-contingently good thing that those who have done wrong should undergo some form of suffering. ${ }^{14}$

Without defending the view, R. Jay Wallace characterizes the thesis of retributivism similarly as

the view that it is intrinsically good that wrongdoers should suffer harm, and that therefore we have a positive duty to inflict such harms on them. ${ }^{15}$

Here, I take Wallace's formulation of retributivism, like Bennett's, to be an instance of an axiological basic-desert thesis.

In what follows, I will advance a variation on an axiological thesis. A weak version would treat the goodness of blaming as a justification for the mere permissibility of blaming, whereas a strong version would have it as a moral requirement, as for example it is expressed in the preceding quotation from Wallace. ${ }^{16} \mathrm{~A}$ middle ground, which I now endorse, is that the goodness of the harm in blaming provides a practical reason favoring blaming. ${ }^{17}$ Favoring practical reasons are of an intermediate strength as between reasons issuing from requirements and the merely weak reason of permissibility. As I understand them, all that is provided by considerations of permissibility is simply that nothing prohibits a certain course of action. Favoring reasons for blaming seem best suited for a thesis about desert. How so? Contending that those positioned to blame have a moral duty to blame is overly demanding to account for our sense of the option of blame in a wide range of cases. But mere permissibility does not capture the force of our reasons to blame. Favoring does. It is plausible, granting the axiological assumption, that if it is in some way good to harm a person by blaming her, the goodness counts as a reason favoring such a course of action, while at the same time not requiring it.

But why adopt any axiological desert-based account of blame? Why not commit to an exclusively deontic version? Because the latter commits to lessin particular, because it makes no commitment to the goodness of the harm in blaming-is it not philosophically easier to defend? Here is an argument. A strong version of an exclusively deontic thesis is a nonstarter for blame. Re-

and Conversation," 133.

Bennett, "The Varieties of Retributive Experience," 147.

Wallace, Responsibility and the Moral Sentiments, 6on13.

E.g., Bennett, "The Varieties of Retributive Experience"; McKenna, "Directed Blame and Conversation”; Wallace, Responsibility and the Moral Sentiments, 6on13.

I am indebted to Ingmar Person for this suggestion. 
quiring others to blame directly the blameworthy places unreasonably high demands on members of the moral community, and most notably those who have been wronged. But a weak version, merely rendering it permissible to blame the blameworthy, only establishes that one would do no wrong to blame. This provides no positive reason to blame. It offers nothing that favors blaming as one of the constitutive features of a desert-based intuition. ${ }^{18}$ Insofar as directed blame involves harm, this sort of normative warrant for directed blaming remains silent on why anyone should do this harm-causing thing. But if blaming involves harming, it seems one should not blame unless she has a good reason to do so; the harming would itself seem to offer a reason against blaming, even if it is permissible to harm. So a culpable person's deserving blame would never outweigh a would-be blamer's reasons to refrain from blaming. ${ }^{19}$ That cannot be right. An axiological version that favors blaming because it is good supplies the sort of reason at issue and so avoids this problem. ${ }^{20}$

One might protest that the preceding argument relies upon a mistaken assumption about what normative work an appeal to basic desert should do. So, the objection might go, basic desert only needs to justify a wrongdoer receiving blame. It need not provide the good reasons one blaming has to blame the per-

A referee for this journal asks why the reason for blaming is not provided merely by the desert base, absent a further presumption that blaming is good. Why, this referee asks, is it not enough of a reason to blame a person that she freely and knowingly acted wrongly, for instance? In a sense, it is. The thesis under consideration is what a claim of desert comes to, of what desert is (as it bears on blame). The claim here, on the imagined weak deontic thesis, is that the desert base provides no more than the following as a reason: that it is permissible to blame. This is tantamount to the weak thesis that, pro tanto, it would not be wrong to blame. My argument is that this is inadequate, since the harm in blaming would then supply a reason (not a requiring reason) not to blame.

19 I am grateful to an anonymous referee for suggesting this way of formulating the point.

20 A referee for this journal has asked whether a deontic thesis cast in terms of pro tanto duties would do work similar to the work I contend is best done by favoring reasons on an axiological approach. Would these weaker duties not give rise to a weak deontic thesis, one that would not be any different from my proposed axiological proposal? I do not think so. Pro tanto duties are still duties, and duties are requirements that, when one fails them, involve wrongdoing. Of course, being pro tanto, they can admittedly be overridden. But absent overriding factors, they are still binding as duties. They are thus not optional for the blamer in a way that is best suited to most instances of warranted blame. Perhaps the preceding is too quick, as Mark Timmons has recently noted in conversation. There are further avenues a deontological theorist might consider. For instance, following a suggestion by David McNaughton (Moral Vision), one might distinguish moral oughts that are required from moral oughts that are simply recommendations. I grant that this is an alternative that one might pursue. If viable, the argument I have offered here would fall short. But this alternative proposal would need to be developed. Regardless, I will not pursue the matter here. 
son who deserves it. Those reasons, it might be argued, are supplied by other factors, such as a wronged person's need to give voice to her own feelings of anger, or to aim at deterrence, or whatever. Perhaps one could regard these as favoring reasons. As such, one might argue, a strictly deontic version merely rendering it permissible to blame could make room for favoring reasons, and so, supplemented by these reasons, provide the practical reasons a blamer might have to do the blaming. But on such a view, strictly speaking, the desert itself, being an exclusively deontic notion, would not issue or be the ground of those favoring reasons.

I find the preceding defense of a deontic version an unsatisfying way to understand the role judgments about basically deserved blame play in our moral responsibility practices. In particular, the reasons favoring blaming when someone deserves blame in a basic sense are dependent on factors that go beyond those bearing on the desert itself. However, I will not pursue the matter any further here. Perhaps after all an exclusively deontic desert thesis is the philosophically wiser option insofar as it does commit to less. It must be granted that it would avoid the seemingly paradoxical issue to be discussed below: that harming itself could be good in a way that is not merely instrumental. Nevertheless, in what follows I will develop a favoring version of an axiological thesis. I offer two motives for pursuing this option, motives that remain even if the argument offered in the two preceding paragraphs proves unsuccessful.

First, there are some whose folk intuitions about desert include a consideration about the goodness and not just the rightness of a blameworthy person getting what she deserves. It is worth examining whether such a view can withstand careful scrutiny even if doing so is not strictly required to make sense of a basic-desert thesis for blame. Second, consider those philosophers who theorize about free will in terms of the control required for basic-desert-entailing moral responsibility. What I suspect many of them have in mind is a thesis about the value of agents getting what they deserve when, acting of their own free will, they knowingly do morally wrong. I am interested in engaging these philosophers and in developing for them a clear specification of what basically deserved blame comes to. ${ }^{21}$

\section{ZEROING IN ON A PRINCIPLE OF BASIC DESERT}

To illustrate the sort of view I will explore hereafter, here is a first pass at a principle restricted to morally wrong acts:

21 One of the referees from this journal has understandably asked for some support of this claim. I confess, I have none, save for some sense from talking with those working in this field. 
D1: Because it is good to harm by blaming one who is blameworthy for a morally wrong act, there is a reason that favors doing so.

D1 does not identify or give the meaning of a desert thesis for blame. This is because it does not in any way express the fitting relation that is supposed to hold, by virtue of desert, between the desert-base involving an agent's morally wrong act and the blaming that is itself that which is deserved. D1 only reports the kind of appraisal—deontological or axiological—a claim of desert is. So, it is best to think of $\mathrm{D} 1$ as entailed by a certain desert thesis rather than identifying it or giving its (complete) meaning. ${ }^{22}$

Note also that D1 is consistent both with a nondesert thesis, and also with a desert thesis that is not basic. To be clear, there are two distinct theoretical alternatives to a basic desert thesis one might consider when seeking to provide the normative warrant for blame. One is to offer an account specifying the appropriateness of blame that makes no reference to desert at all. ${ }^{23} \mathrm{~A}$ different approach involves arguing that there are more basic normative principles providing the underlying rationale for claims of what is deserved, and hence for propositions such as D1. This would amount to a nonbasic desert thesis. How so? The good mentioned in D1 could be construed as an instrumental good, and then justified by reference to, for example, utilitarian or instead contractualist principles. On this approach, there would be important content to claims of desert that relate desert-bases to what is deserved in the proper sort of fitting manner. But the practices and underlying rationale for the claims of desert, and for a principle like D1, would themselves be grounded on something that is more fundamental. ${ }^{24}$

Building upon D1, here is a revised principle more carefully suited just for basically deserved blame:

D2: Because it is intrinsically good to harm by blaming one who is blameworthy for a morally wrong act, there is a reason that favors doing so.

One way to construe the thesis, then, is that the goodness identified in D1 is grounded in desert. Careful attention from a referee for this journal helped me see the benefit in explaining the thesis in these terms. Consider, for instance, a view like Smart, "Free-Will, Praise and Blame." This is roughly what Rawls has called post-institutional desert (A Theory of Justice, 103-4). James Lenman, for instance, has explored an interesting nonbasic desert thesis for blame by appeal to contractualist considerations ("Compatibilism and Contractualism"). In my estimation, this is how one should understand Wallace, who rests claims of desert on considerations of fairness (Responsibility and the Moral Sentiments, 227). More recently, Manuel Vargas, Building Better Beings, has advanced a nuanced consequentialist alternative. 
Some will object that harm to a person is never intrinsically good. ${ }^{25}$ But to appreciate what those wishing to endorse $\mathrm{D} 2$ might have in mind, we can understand claims of intrinsic goodness in terms of cross-world differences. To illustrate, consider just for a moment not blame but instead punishment. Grant that it harms a person to sit in prison for five years; he is made to suffer in his isolation. Is this intrinsically bad? Suppose it is. But now consider instead a person who sits in prison for five years in response to having brutally raped someone. Here is a way to appreciate the claim of intrinsic goodness in D2: all things being equal, it is a better world that this rapist sits in prison for five years for his act of rape than a world in which this same rapist causes the same harm to his victim but undergoes no harm himself. That is fitting. Furthermore, in keeping with D2, because it is intrinsically good as a fitting response to the harm he caused, there is a reason that favors his being harmed. ${ }^{26}$

\section{MORAL RESPONSIBILITY, BLAMEWORTHINESS, AND BLAME}

Given the preceding discussion of basic desert for blame, consider now blameworthiness and blame. Basic desert is alleged to provide the (or at least a) normative warrant for blame as a response to the blameworthy. To understand what basically desert-entailing moral responsibility is, we need an account of the pertinent relata: blameworthiness and blame. Here I summarize my own Strawsonian-inspired, communication-based theory. ${ }^{27}$

To begin, I endorse the widely shared Strawsonian thesis that attention to a special class of emotions is integral to our understanding of moral responsibility. ${ }^{28}$ Here our interest can be limited to the reactive attitudes of resentment

25 E.g., see Scanlon, “Giving Desert Its Due,” 102.

26 Does this mean that it is not intrinsically bad that this criminal sit in prison for five years? No. It can be granted that incarceration is always an intrinsic bad. Still, that very thing, as a response to a crime, might be good as well along some other dimension. The appeal to a cross-world comparison between a world where the criminal is not punished and a world where he is helps to bring this out. I am indebted to a referee for this journal for encouraging me to clarify this point.

27 McKenna, Conversation and Responsibility. Several other philosophers have also endorsed and developed some variation on a communicative theory of moral responsibility, and much of what follows could be fitted for their views as well (e.g., Bennett, "The Varieties of Retributive Experience"; Macnamara, "Reactive Attitudes as Communicative Entities"; Shoemaker, Responsibility from the Margins; and Watson, "Responsibility and the Limits of Evil."

28 E.g., Strawson, "Freedom and Resentment"; Watson, "Responsibility and the Limits of Evil"; Wallace, Responsibility and the Moral Sentiments; Fischer and Ravizza, Responsibility and Control; Shoemaker, Responsibility from the Margins. 
and moral indignation as they bear on blame. I note four features bearing on the discussion to follow.

First, an episode of one of these reactive attitudes is an affect-laden negative reaction in response to the presumption of another's objectionable quality of will, typically, but not always, for a wrong act. The response is in some way dependent upon, or normatively assessed in light of, a cognitive judgment of some sort, such as the judgment that an agent has done wrong.

Second, quality of will concerns the regard or lack of regard for others' interests and for salient moral considerations. Quality of will is not limited to the rightness or wrongness of an agent's act; it also includes, for example, her concern for or attitude regarding the rightness or wrongness of her act.

Third, the exemplar cases of these emotions, the ones that should be central to a theory of moral responsibility, are the ones that are publically manifested in outward behavior, and are directed at one who is blamed. These are the ones that pertain to what early on I identified as directed blame. Of course, there are private episodes of these emotions, but it is the overt ones, displayed in behavior, that are especially salient. More particularly, of these overt episodes, it is the directed ones, exhibited in the presence of the blamed and suitably directed as modes of blaming, that are crucial. ${ }^{29}$

Fourth, the overt manifestations of these emotions are best understood as practice dependent. They involve alterations to interpersonal practices constitutive of adult interpersonal life. Such alterations to these practices help make manifestations of these emotions intelligible as the sorts of emotions they are.

Reacting to a blameworthy agent with a reactive attitude like resentment or moral indignation has an expressive and communicative role. This is a point Gary Watson emphasized in his development of a Strawsonian theory of moral responsibility. ${ }^{30}$ In typical cases, an episode of resentment expresses an agent's moral concerns - her demands, expectations, regard for a blameworthy agent's moral violation, and, most importantly, her concern for the blameworthy agent's morally objectionable quality of will. Not only do manifestations of these emotions in our blaming practices express these things, they also serve a communicative role: they communicate our concerns by way of our altered regard toward the agent and her conduct in reaction to her blameworthy conduct. The manner of expression and communication is by way of altered interpersonal practices characteristic of the otherwise normal modes of conduct we engage in when dealing with each other. Normal courtesies might be withheld, friendships dis- 
solved or attenuated, direct expressions of anger put on full display. All of these, in both word and deed, serve expressive and communicative roles.

Drawing upon the expressive and communicative nature of the morally reactive attitudes, I have proposed a bolder thesis: that the distinctive expressive and communicative nature of these attitudes-in their directed manifestations and within the context of a set of social practices - can take on something analogous to a conversational role. In particular, they can be understood on analogy with a stage in a conversation in which one responds to an interlocutor who has antecedently initiated a conversation. The basic proposal works like this: the actions of morally responsible agents are candidate bearers of a species of meaning — agent meaning - where meaning is a function of the quality of the will with which an agent acts. An agent's engaging in (seemingly) blameworthy conduct can be understood on analogy with a speaker of a natural language initiating a conversational exchange by way of saying something meaningful. When others then react by holding an agent morally responsible, by manifesting their reactive attitudes in cases of directed blaming, their responses can be understood as meaningful replies to the agent who initiated the "conversational exchange." When the (putatively) blameworthy agent then offers an apology, an excuse, a justification or admission of guilt, a defiant dismissal, or whatnot, this can be seen as a reply and thus a further extension of the evolving conversation.

One of the norms governing (the analog to) a conversational exchange will be informed by the meaning of the agent's action as indicative of the quality of will with which she acts. Some blaming responses will be especially suited as intelligible, even insightful, replies to the agent, just as sometimes, in conversation, one knows just the right thing to say in reply to her interlocutor so as to speak directly to exactly what was originally meant. Other blaming responses will be infelicitous insofar as they fail to appreciate the actual meaning of the agent's act. Indeed, it seems that the way excuses and justifications work attests to this point. In different ways, both show that an agent's action did not manifest the lack of moral regard for others that the content of a (sometimes preliminary) blaming response is premised upon. Also, the meaningfulness of a directed episode of resentment or instead moral indignation will be a function of the background social practices and expectations against which alterations will be seen to have a particular salience.

Here is an example I have used elsewhere. ${ }^{31}$ Two friends meet for coffee, and one, Daphne, is offended by a racist remark (she believes) Leslie makes about Hispanics. Daphne's indignation is then manifested in part by her not inviting Leslie to lunch as she normally does, along with a mutual friend of theirs who is

31 McKenna, Conversation and Responsibility, 70. 
Hispanic. Daphne's failure to invite Leslie gains its meaning in part by the background assumption that they typically go to lunch together, and in part by the meaning she assigns to Daphne's remark.

One more point before proceeding: blaming is taken to have a characteristic force, a sting that is liable to harm the one blamed. How do the elements of the conversational model figure in an account of that harm? Put simply, according to the conversational model, how does blame hurt? Drawing upon Joel Feinberg's notion of welfare interests, and assuming that we can understand harms as setbacks to interests, I find three distinctive harms that blaming is liable to cause when we understand blame to have the conversational features I contend it has. ${ }^{32}$ First, it impedes a blamed person's ability to exercise her capacities to engage in normal social intercourse. Why? Part of the expressive and communicative elements invoked in "conversing" by blaming involve our inclination to withdraw from or instead revise otherwise normal social relations with the one blamed. Second, a person's freedom to live her personal life as she wishes is impeded. Demands that one respond to another's charge of wrongdoing, that she apologize or account for herself, are liable to interfere with living her personal life as she pleases. Third, these sorts of demands and revisions to the expected interpersonal relations among others are emotionally taxing; they affect, or at least are liable to affect, one's emotional stability. So, in summary, on the conversational model, blame is liable to cause three distinctive sorts of harms by threatening the following welfare interests: the ability to engage in normal social intercourse, the freedom to live one's personal life as one wishes, and the preservation of emotional stability.

\section{THE DIFFERENCE BETWEEN BLAME AND PUNISHMENT}

The preceding details offer enough resources to fit the conversational theory of moral responsibility for a basic-desert thesis for blame. Before turning to that topic, however, I pause to note the way in which blame differs from punishment according to the conversation theory. This is not a minor point. Some philosophers treat blame as informal punishment. ${ }^{33}$ In doing so they fix on the idea that blame is a species of sanction. But this gives added reasons for critics of desert-based theories of moral responsibility to damn claims of basically deserved blame by way of arguing against desert-based theories of punishment-especially full-blown retributivist theories. To the extent that blame differs from punishment, it might well be that the features of punishment that critics of retribu-

32 Feinberg, Harm to Others, 37-38; McKenna, “Directed Blame and Conversation," 134-41.

33 E.g., Feinberg, Doing and Deserving. 
tivist theories find especially objectionable are lacking from blame's nature, and by extension, the norms governing its application.

On the conversational theory, blame is a stage in a dynamic, unfolding conversation (conversational analog), and it plays a role in that exchange at an intermediary stage. At the first stage, Moral Contribution, a morally responsible agent performs an act that has agent meaning of a sort that invites the defeasible thought that she is blameworthy. At the second stage, Moral Address, another holding her morally responsible addresses her and expresses her resentment or moral indignation. Here is the blaming stage. Then at a third stage, Moral Account, the blamed agent offers an account, a reply to the blame, in the form of an apology, an excuse, a defiant admission of guilt, and so on. On my view, at least in typical cases, punishment is yet a further stage in the unfolding conversation. Its conversational meaning is a response not just to the wrongdoing that instigated the exchange, but also to the account offered at the third stage, Moral Account, wherein the blamed party replies to those blaming her. Punishment's meaning encompasses more than does blame's. (This is analogous to the way conviction and sentencing are treated in the law.)

Here, now, are two ways that on my view blame differs from punishment. First, the harms to which a wrongdoer is exposed in our blaming practices are limited to the range of welfare interests delineated in the preceding section. While this range of harms is after all substantial, and can "really hurt" as the saying goes, there is nevertheless an upper limit on such harms that is lacking in the case of punishment, which can include physical harms, confinement, monetary sanctions, obligations for community service, probationary periods, and formal means of banishment from organizations. Second, and perhaps more important, by its very nature punishment involves the intention to harm. But at least on the conversational model, blame need not. Blaming involves expressing and communicating one's regard for a blamed party's quality of will. It involves the conversational expectation and presumed burden of a reply from the blamed party. But its aim need not be to harm; its aim need only be to converse, to engage, to demand, and so on. Naturally, it is reasonable to think that competent moral agents engaged in blaming practices will understand that their blaming is liable to harm the one blamed. And so they are likely to harm knowingly. But what we do knowingly is much wider than what we do intentionally. Hence, punishment essentially involves the intention to harm as a means of sanction; blame does not.

\section{FITTING THE CONVERSATIONAL THEORY FOR A BASIC-DESERT THESIS}

In fitting the conversational theory of moral responsibility for a basic-desert the- 
sis, I aim to avoid opposing charges from two different critics. There are those who would reject a basic-desert thesis for moral responsibility because basically deserved blame involves a host of objectionable features that it shares with basically deserved punishment. Then there are those who would reject the conversational theory of moral responsibility if it fell shy of a theory that included basic desert for blame.

\subsection{Resisting the Charge of Overcommitting}

As for the critics who are against a basic-desert theory of moral responsibility because of its unsavory alliance with basically deserved punishment, what features of punishment might make it so objectionable? There are several potential candidates. One has to do with responding to a wrongful harm with a like harm: an eye for an eye. If, as the objection goes, justice is unpacked in terms of basic desert, and this is what desert comes to, justice commands acts of barbarism. There are, furthermore, worries about proportionality, of responding to a wrongful harm with a harm of the same degree. So those who torture and maim must somehow be caused harm proportionate to what they caused? Who is to shoulder this burden? Then there is the thought that justice would command intending to harm the one to be punished. Is this bloodlust? Vengeance? Even if neither, is it not just cruel? An extreme view would have it that to account properly for true moral responsibility one must be able to make sense of a blameworthy person's not just basically deserving blame, but more drastically, as Galen Strawson would contend, the intelligibility of deserving eternal punishment in hell. ${ }^{34}$

If any of the above reasons are what motivate some to reject a basic-desert thesis for punishment, none translate to the activity of directed blaming on the conversational model. If blaming functions on analogy with a conversational response to one who initiated a conversation, the proper metric is to be understood in terms of the intelligibility or meaningfulness of a reply that extends the conversation. It is not a matter of "saying" to the one who introduced the initial meaningful contribution just what she said back in reply. It is a matter of responding in a way that fits the salience of that contribution in a manner that gives expression to the blamer's demands, expectations, and so forth. Here also it is hard to see how this can be put in terms of proportionality of harm. It is better to think of any sort of proportionality in terms of the severity of the response being adequate to convey meaningfully the blamer's disapproval, her hurt feelings, and so forth. Also, as noted in the previous section, worries about the extreme severity of deserved harm are out of place. The range of harms the activity of blaming can cause according to the conversational model are limited

34 Strawson, "The Impossibility of Moral Responsibility." 
to the range of welfare interests identified above. Finally, as noted in the previous section, unlike punishment, on the conversational model blaming does not require the intention to harm. So charges of being essentially rooted in vengeance are unfounded. All of these considerations suggest that the pertinent harms in blaming should not be indicted with the harms that are taken to flow from basically deserved punishment.

One serious philosophical worry about the very nature of basically deserved blame arises from the idea that harm of any sort could ever amount to an intrinsic good. All harms, so the objection might go, only aggregate along the negative evaluative dimension of badness, negatively adding to any harm already done. Here reasonable minds can differ, and the best way to illustrate this is in terms of the claims of cross-world difference noted above (section 3 ). But now we can do so, not in terms of a case of punishment, but in terms of a case of blame. Consider a case in which one performs a blameworthy act, say, making a hurtful, racist remark. Now consider two worlds, one in which the wrongdoer is in no way harmed in response to her remark. There is just the harm she causes, and no harm that accrues to her. Then consider another in which the wrongdoer is harmed in response to her wrongful harm in only the following ways, and only assuming that some sense of proportionality in the response is achieved: by others blaming her, her ability to engage in some spectrum of social intercourse hampered, her freedom to live her personal life as she wishes disrupted, and her emotional stability unsettled. Hold in mind, in imagining such a case, that the degree of these harms might also be fairly minimal and so would fall far shy of anything like extreme suffering. I fully acknowledge that some are likely to claim that indeed the first world is a better world. Adding one harm to another, they might argue, only increases the amount of intrinsic badness in the world; no intrinsic good can come from the addition. But I disagree. There is something fitting about a world in which a blameworthy wrongdoer is made worse off in just the limited ways identified here. That world is a better world than one where the wrongdoer is in no way harmed. Why? Well, one might say, because she deserves it.

\subsection{Resisting the Charge of Normative Inadequacy}

What of those who would reject the conversational theory because it falls shy of a basic-desert thesis? There is a fair complaint about the bare bones of the theory as set out thus far - that is, when it is not explicitly fitted for a basic-desert thesis. The conversational features of the theory unpack claims of appropriateness in a particular way. So they aid in giving some informative content to the claim that blaming is an appropriate response to one who is blameworthy. Conversational meaningfulness or intelligibility is a thick, informative notion. Indeed, some 
who are foes of a desert thesis of any sort might point to the norm of intelligibility as a way to account for the fittingness of blame in the absence of any claim of desert. But the problem is that intelligibility or conversational meaningfulness is just not the right sort of normative warrant to engage in a practice whose nature involves harming those at whom it is directed. Some further normative warrant is needed, and so it seems the resources of the conversational theory cannot by themselves justify the harms in blaming, even if the harms that are identified are harms that flow from the conversational nature of the activities associated with directed blaming.

This seems right. The conversational theory of moral responsibility needs supplementing with normative resources that reach outside the conversational elements of the theory. My own view is that this can be done with resources that do not require commitment to basic desert. ${ }^{35}$ One can do so by appeal to exclusively nondesert-based resources. ${ }^{36}$ Instead, one can do so by appeal to nonbasic desert resources. ${ }^{37}$ Nevertheless, as I now argue, one can also supplement the conversational theory by way of a basic-desert thesis. The proposal is simple: Take the harms I have identified in directed blaming on the conversational theory. Now add the claim that one who is blameworthy deserves just this limited range of harms, in the basic sense of desert. I offer only two points to develop this proposal.

First, consider the norm of conversational intelligibility or meaningfulness as a fitting response to a meaningful contribution - the contribution being the presumed agent meaning of the blameworthy agent's act. The conversational theory offers an illuminating way in which the elements of a desert-base can be said to fit in a case-specific manner the deserved response. Recall that early on (section 1) I noted that it is especially difficult to state the way in which a particular deserved blaming response could, in a case-specific fashion, be fitted for a particular desert-base. In this respect, the conversational theory offers an elegant way to capture this. It is the sort of fittingness that uniquely pairs a particular conversational reply intelligibly for a prior particular meaningful contribution. In this respect the current basic-desert thesis for blame appears to avoid rather easily a (perhaps surmountable) problem for theories of punishment. How so? It is a truism to claim that, on a retributivist theory of punishment, the punishment should fit the crime. And this normative requirement of fit does seem to be motivated by the thought that this is a matter of what one who is to be punished

McKenna, Conversation and Responsibility.

À la the work of a philosopher like Scanlon, What We Owe to Each Other.

À la the work of someone like Lenman, "Compatibilism and Contractualism"; Wallace, Responsibility and the Moral Sentiments; or Vargas, Building Better Beings. 
really deserves. But with punishment, it is often hard to capture this. A person imprisoned for armed robbery might get five years, and so might a rapist or a corrupt banker. Where is the special fittingness between punishment and crime? Of course, this is not to say that properly justified forms of punishment could not be so tailored, but it stretches the imagination to think of how this could be so. On the conversational theory of moral responsibility, there is an elegant way of conceiving of the special fittingness relation between an agent's blameworthy act and the blame she deserves.

Second, consider a principle like D2, which I offered as a way to understand a basic desert thesis for blame:

D2: Because it is intrinsically good to harm by blaming one who is blameworthy for a morally wrong act, there is a reason that favors doing so.

It is easy to see how it might be altered to fit the conversational theory, as follows:

$\mathrm{D}^{*}$ : Because it is intrinsically good to harm by blaming one who is blameworthy for a morally wrong act (where the harms in blaming are limited just to those identified on the conversational theory), there is a reason that favors doing so.

I offer $\mathrm{D}^{*}$ as an initial formulation.

Elsewhere, I have offered three observations to establish the claim of goodness as captured in thought experiments like those involved in the cross-world comparisons offered above (section 4$).{ }^{38}$ These goods are meant to function as markers for or evidence of the good referenced in a principle like $\mathrm{D} 2^{*}$. Here are three goods that can be cited when someone asks, "Why are the particular harms of blaming good?" First, it is good for the blameworthy agent that she is harmed in the ways unique to directed blame on the conversational theory. This is because the potential harms to which she is exposed, such as the ability to engage in normal social relations with others, are harms to her only insofar as she is committed to membership in the moral community. Her liability to such harm is an expression of her being so committed. That is good. Second, it is good for the one blaming insofar as one's blaming is motivated by and an expression of one's commitment to morality. That too is good. Third, and finally, the relationship between blamer and blamed in the practice of blaming is itself part of an activity whose aim is to ameliorate and sustain the bonds of moral community. ${ }^{39}$ That also is good. (I defend these claims below.)

McKenna, Conversation and Responsibility, 167-70.

See Christopher Bennett's development of a basic desert thesis ("The Varieties of Retributive Experience”). Bennett makes the aim of our blaming practices moral reintegration, and 


\section{A SERIOUS CHALLENGE: ARE THE GOODS AT ISSUE \\ REALLY SUITED FOR BASIC DESERT?}

Note that $\mathrm{D}_{2}{ }^{*}$ is formulated in terms of intrinsic goodness. As such, it is not well suited for the conversational theory. Consider the nature of the harm that, I contend, is good. On reflection, it is a distortion to describe its (disputed) value as intrinsic. Why? The nature of the thing that is claimed to be good, the harm issuing from the conversational dimension of the blaming activity, gains its nature as a communicative and conversational response only by virtue of its relation to a collection of practices and norms against which the blaming activity can have a salience. Furthermore, insofar as its status is part of a stage in an unfolding conversation (or analog to one), it depends on what transpired prior to it as a meaningful contribution, and expectations about what might unfold after it, as felicitous as in contrast with infelicitous responses, for instance. So it seems that its status as good is, after all, extrinsic, not intrinsic. Note, furthermore, that the goods I offered as evidence for the goodness of the harm in blaming were all in some way characterized in terms other than those internal, intrinsic features of the harm. All were in some way extrinsic. I drew attention to the agent's commitment to moral community, or the blamer's commitment to morality, or the way the interaction between blamed agent and blamer involves an activity aiming to sustain the bonds of moral community.

If what is required of a basic-desert thesis for blame is that the good in the harm of blaming is intrinsically good in a strict sense, then I have after all fallen shy of a basic-desert thesis. Derk Pereboom, for instance, often writes of a basic-desert thesis for blame in such a way that if an agent is blameworthy for an act in the basic-desert-entailing sense, then she deserves blame just because she so acted. ${ }^{40}$ Here, the "just because" invites the reading that the ground for the desert, found within the desert-base, and any claim of goodness entailed by what is deserved, cannot reach beyond the mere fact of the agent's so acting. Pereboom, it seems, requires that any good implicit in judgments of deserved blame has to be intrinsic in the strict sense.

In response, I propose a more liberal view of the value of blame. In her influential paper, "Two Distinctions in Goodness," Christine Korsgaard points out that the distinction between intrinsic and extrinsic goodness differs from the distinction between noninstrumental and instrumental goodness. ${ }^{41}$ Something

treats this as something that is good, and not merely for consequentialist reasons. Clarke,

"Some Theses on Desert," draws upon a similar point.

E.g., Pereboom, “Free Will Skepticism, Blame, and Obligation,” 189.

Korsgaard, "Two Distinctions in Goodness.” 
might be noninstrumentally good since its goodness is not in the service of another thing, and yet its goodness might be dependent upon its extrinsic relation to other things. A simple example might be the beauty of a rare flower, whose beauty would not be so precious if flowers of that kind were commonplace. Another, I have suggested, is a musician's contribution to a musical piece, where the contribution gives meaning to but also acquires meaning from the accompanying instruments. My example is the drum work by Joe "Philly" Jones on John Coltrane's album Blue Train. ${ }^{42}$

Given this distinction, in earlier work I suggested, but did not develop, a basic-desert thesis in terms of noninstrumental value. ${ }^{43}$ Here is a revision to $\mathrm{D}_{2}{ }^{*}$ revised to accommodate this more permissive conception of basically deserved blame:

D3: Because it is noninstrumentally good to harm by blaming one who is blameworthy for a morally wrong act (where the harms in blaming are limited just to those identified on the conversational theory), there is a reason that favors doing so.

Does my concession that the pertinent good is merely extrinsic and not intrinsic weaken my thesis? Is D3 not exposed to the indictment that the particular extrinsic facts that would ground a claim of goodness are also facts that show the good to be not merely extrinsic but, contrary to my contention, instrumental? In short, the charge might go: It is all well and good to distinguish between extrinsic and instrumental goodness. But drawing the distinction does not mean you can carry it off in this case. If the goodness of the harm you identify in blaming gains all of its value exclusively from serving the elements extrinsic to it, then it is not merely extrinsically good; if good at all, it is only instrumentally good.

So it seems I have two burdens. One is to resist the thesis that anything shy of a strict claim of intrinsic goodness falls short of a proper basic-desert thesis. Recall, this arises from Pereboom's "just because" formulation, which seems to limit the thesis to intrinsic rather than any sort of extrinsic but noninstrumental good. On this view, while $\mathrm{D}_{2}{ }^{*}$ might be a serious contender, D3 is not, and all the conversational theory offers is something like $\mathrm{D} 3$. Another, assuming the first burden can be met, is to resist the worry that the goods I have identified as extrinsic but noninstrumental are upon examination merely instrumental goods and nothing more. 
Consider the first burden. Citing a good that is an extrinsic but noninstrumental good located in the harm of blaming would be enough to foreclose the worry that the good only gains its value by serving a consequentialist or contractualist end. Indeed, when Pereboom makes these claims about intrinsic goodness, he almost invariably clarifies by writing of the sense in which it differs from goods that could be justified by consequentialism or contractualism. ${ }^{44}$ His most immediate worry seems to be that there is some more general moral theory or more general moral principles providing the justification for blaming, and any goodness in blaming gains its value from that theory or those principles. The extrinsic goodness figuring in the proposed conversational model is not meant to serve an instrumental purpose in relation to other general moral theories or principles.

Furthermore, consider use of the expression "just because" when Pereboom claims that, according to a basic-desert thesis, an agent would deserve blame just because she so acted. It is not clear that we must understand the "just-because" relation so that it rules out the relevant value of the blame being extrinsically related to other things. It might function like an indexical, picking out what can be added, holding fixed other features of a system or set of relations that would then give something a certain value. Granting, for example, that there are so few flowers of a certain sort, and holding fixed other standards of beauty viewers might take to evaluating flowers, with all that in place, one might think a flower, growing alone in an open field is beautiful just because it is located there. This might be so for the goodness found in the activity of blaming. Under the assumption that the practices and norms set context and salience for a blaming response, and they provide the constitutive resources to give the response meaning, one might say, adding the response of blaming is fitting — and deserved — just because the agent so acted.

Now consider the second burden. In assessing an earlier formulation of my proposal, Pereboom argued that the value in the communicative and conversational dimensions of the blaming activity, and the harms that attend it, are limited to instrumental goods. ${ }^{45}$ For instance, I cite the good in the blameworthy agent's commitment to membership in the moral community, claiming that it is noninstrumental. Pereboom replies:

On the basic desert view, it is good that the blameworthy agent is harmed 
in the ways indicated just because he has knowingly done wrong, and in the context of the debate, this is just what it is for such a harm to be a noninstrumental good. Harm aimed at the good of membership in a moral community would, by contrast, be instrumental, since the harm is not envisaged as good in itself but instead as serving the good of such membership. ${ }^{46}$

Then, in response to my contention that the harm in blaming encompasses a range of noninstrumental goods whose status is dependent upon its relation to others and to sets of practices (and thus is good extrinsically), he writes:

While it is plausible that certain kinds of obvious goods, such as mental and physical health, are partially constitutive of the noninstrumental good such as human flourishing, it is at least typically less credible that harms - as harms - are partially constitutive of noninstrumental goods, and for this reason count as noninstrumental goods themselves. Vaccination may be a prerequisite of physical health, and health constitutive of flourishing, but it is not plausible that the pain of vaccination is constitutive of flourishing, by contrast with being instrumentally required for it. ${ }^{47}$

Pereboom's criticism crystallizes the sort of objection I indicated above: granted, there are noninstrumental goods whose status is extrinsic, but the harms I have identified in the practice of blaming according to the conversational model are not among them.

I offer two points in reply. First, as I have noted previously, the goods that I contend are at issue might well be of a "mixed" variety, and so might thus serve some instrumental purposes. ${ }^{48}$ But they might also have noninstrumental value. Crucially, something can be of value because of the aim it takes on or its role in a practice with a certain telos - such as aiming at preserving the bonds of moral community - and have that value regardless of whether it actually helps to attain that end. Its value is in its commitment to that telos, and (not just) in its instrumental efficacy of achieving the desired end.

Second, recall the cross-world thought experiments I proposed to make sense of how one harm in response to another could constitute a good. Of course, I had originally put that in terms of capturing a sense of intrinsic value. But it can be employed to help establish similar claims about extrinsic, noninstrumental value. The cross-world comparisons just have to include in one world,

McKenna, Conversation and Responsibility, 170. 
and exclude in another, the extrinsic relations to the pertinent harmful activities that are alleged to issue in the good-making feature. To be clear, what is it that is a candidate for a noninstrumental good? It is the harm itself as it contributes to the blaming activity, an activity that is in response to, and so is extrinsically dependent upon, an antecedent blameworthy act. Bearing this in mind, Pereboom contends that it is less credible that harms can be partially constitutive of a noninstrumental good, as in comparison with certain benefits that can be partially constitutive of a noninstrumental good. As quoted above, he illustrates with a simple case of the pain of vaccination (a harm), which is only instrumentally good in the service of health and human flourishing. This is a powerful challenge, but note that it turns primarily on the force of the sort of example he enlists.

Here is different sort of case. Consider grief as a response to the loss of the parents one loves, or in response to losing a sibling early in that sibling's life. Grief as part of the good of living a flourishing life might be seen as a noninstrumental good insofar as it is bound up with accepting the realities of our loving relations and our finitude. Grief is certainly a harm, but sometimes it is also a good, a noninstrumental good connected with accepting our humanity. Consequences aside, a life without grief in response to losing the ones one loves would be worse than one where, in the face of loss, one underwent an appropriate period of psychological pain and mourning. One who would not mourn the loss of their mother, for instance, is one whose life is in some way impoverished. Or at any rate, even if one disagrees, one can see the point of this sort of claim. The harm in blaming, a basic-desert theorist might argue, is like that. It is intimately connected with commitments and modes of life within a moral community whose aim is itself good—and good not merely as an instrument for something else. Crucial to this test case for resisting Pereboom is the idea that grief might very well contain an element that is noninstrumentally or intrinsically bad while nevertheless contributing to a whole that is intrinsically or noninstrumentally good.

I take the preceding case of grief to be adequate to respond to Dana Nelkin's challenge to my view. ${ }^{49}$ However, exploring how she might resist me will help sharpen my thesis. Like Pereboom, Nelkin also wishes to resist my claim that pertinent harms are good. Nelkin contends that the goods I identify in blaming, such as the care a blamed person might have for others' regard, can indeed be noninstrumentally good. And it might well be, she contends, that the harms that attend them come with these goods as manifestations of them, but it just does not follow from that that the goods I identify are good in virtue of these harms. Hence, it is, for instance, the caring about others that is, as she puts it, fundamentally good and not the harm that, she grants, may be non-contingently related to

Nelkin, "Moral Responsibility, Conversation, and Desert." 
it. This is an excellent way to capture what is at stake. It poses a serious challenge to my contention that there are these goods-as-harms identified in the practices of blaming. In the case of grief, the challenge might go, what is fundamentally good is one's caring for family or friends, and a life that involves the attendant intimacies that promote one's flourishing. The pain or harm of loss might be non-contingently related to this thing of fundamental value, given the fragilities of our human lives, but it simply does not follow that it is itself good.

Now why take grief to be the right sort of case to resist Nelkin's insightful challenge? Rather, does she not show precisely why my appeal to a case like grief falls short? I grant, on its face, it seems to. Before offering a direct reply, note the following qualification: it is consistent with my view that it would even be a better world if it were the case that one could enjoy and celebrate the goods of family and friendship without the liability to grief. This might fallaciously lead one to think that in a world where there is the good of friendship and familial love that is accompanied by the pain of loss, that the pain or loss itself could not be noninstrumentally good in any way as a mode of contributing to one's caring and loving. But this is just not true. Were we differently and perhaps better equipped beings, we might not be exposed to these vulnerabilities. But given that we are so exposed, there is the question of whether the harm attendant with grief due to caring can be a noninstrumental good.

I turn now to my direct reply. Critics such as Nelkin appeal to an enticing analytic move by distinguishing the dimension of, say, grief that is appealing or seemingly good-making, which is the caring, and then separating that from the dimension that is unappealing and so seemingly bad-making, which is the distinctive pain of loss. This allows Nelkin to contend that any goodness in grieving (or blaming) is a goodness in virtue of just that dimension, the caring dimension, not the other dimension, the one to which we are averse, the painful ingredient. But I reject this analytic move, this prying apart of the good-making feature as distinct from the alleged bad-making feature. Of course, it will not help merely to contend that, in certain cases, the alleged bad-making feature is necessary or non-contingently related to the good-making feature. Nelkin grants that. Instead, the burden here is to show that the relevant harm actually contributes to the goodness. And in response, what I wish to say is that, as a distinct thing, it would not. Merely as harm, it would not contribute to any goodness. But what a basic-desert theorist can say instead is that it is mistaken to infer from the fact that we can identify these different dimensions of grief or blaming that these can be understood as fully distinct ingredients - like separate ingredients added together to bake a cake-rather than as a unity whose whole has a value that is not analytically decomposable in this way. They are not like separate parts that just "add up." 
I suggested above that the liability to certain harms can be an expression of one's cares. Furthermore, the propensity of others to blame and in doing so harm is a way of registering the concern of the community of blamers. One way to understand this is that such expression is itself, accompanied by these distinctive harms, noninstrumentally good as an organic unity. It would not be good as that particular expression of one's cares absent its expression as a form of harm or suffering. When considering the nature of value as it bears upon the problem of evil, Marilyn Adams usefully draws on a distinction introduced by G.E. Moore and Roderick Chisholm. ${ }^{50}$ There is the evil that is balanced by a greater good, but there is also evil that is defeated by what is good, and in this defeating, one finds a kind of goodness. So too with grief. There is pain in grief on particular occasions, and so a kind of harm, even something that, it can be granted, is intrinsically bad, but as an expression of this way of caring for this person who suffered this loss, it is a "bad" or an evil that is not merely outweighed but defeated. The key distinction between merely outweighing and defeating is that in outweighing a good can be considered as making a positive contribution whose value is not dependent on the bad. The thing of disvalue could, so to speak, be subtracted and the good still stand. ${ }^{51}$ In defeating, the good gains its significance as a good by being a response to and finding goodness built from the thing of disvalue. So, for instance, in expressing one's affections, in expressing one's love when undergoing a period of grief, that pain in loss counts in the context of that set of extrinsic relations as something that is good given the good of the grieving response. So too, I would say, for the harms I have identified in the activities of blaming according to the conversational model. Yes it is, for instance, a harm for the one blamed that she suffer the setback of others distancing themselves from her, but as this harm for her is also an expression of her concern for others, it likewise counts as a good that she is harmed in this way.

\section{CONCLUSION}

I offer the preceding as an account of basically deserved blame. On my proposal, what a blameworthy person deserves in a basic sense is a directed blaming response of a conversational nature, one that engages the blamed person in such a way that she registers the moral demands and concerns of those engaging her. Moreover, the harms that she is alleged to deserve-insofar as she deserve blame tinction introduced by Moore (Principia Ethica) and Chisholm ("The Defeat of Good and Evil"). 
and not also something more like punishment-are exhausted in the activities of blaming her, and of her registering them as such. These are social harms regarding the blamed person's relations with others. When expressed in a fitting fashion, say by pertinent conversational standards of intelligibility or meaningfulness, they engage the person as a moral agent and as a member of the moral community, or at least a potential member.

In developing this view, I have committed to the axiological thesis that when deserved, the pertinent harms of blaming are noninstrumentally good. Many, I suspect, will reject this ingredient as a veiled form of barbarism justifying vengeance and inclinations toward brutality. Indeed, as noted above (section 1), when considering a value-based conception of blame, Scanlon was emphatic in distancing himself from any such view about the goodness of causing the blameworthy to suffer. ${ }^{52}$ So too for Wallace. ${ }^{53}$ Maybe after all this is the correct view, and so maybe one should, as Scanlon did in later work, opt for an exclusively deontic version of a desert thesis for blame. ${ }^{54}$ But note two considerations before rejecting an axiological view of the sort I have defended.

First, one should bear firmly in mind that the axiological claims of noninstrumental goodness involved in the desert thesis presented here are quite limited. What does a blameworthy person deserve on this view, and what would be noninstrumentally good for her to receive? No more than what is involved in that person having a proportionately pained response to others altering their interpersonal relations with her-and altering them as would befit their communicating to her their moral demands and concerns from a place of proportionate moral anger. That is all. No aim of writhing on the floor or the demand for the wearing of hair shirts is part of the mix.

Second, those favoring an exclusively deontic version face burdens of their own. As I argued above, if a strong version is ruled out for deserved blame, what is left is a weak version permitting but not requiring blaming the blameworthy. But merely permitting that the blameworthy be harmed by blaming supplies no reason why one blaming should harm them. So how do the exclusively deontic theorists avoid the charge that they are the ones who permit gratuitous harm under the banner of desert? They cannot really say it is not gratuitous because the person deserves it, since the deserving itself is — by hypothesis — no reason to favor treating the person in that way. So there is some reason to worry that it is after all the exclusively deontic versions of a basic-desert thesis that might just help to conceal barbarity and vengeance.

52 Scanlon, What We Owe to Each Other.

53 Wallace, Responsibility and the Moral Sentiments.

54 Scanlon, Moral Dimensions. 
I close with one final point about whether anyone deserves blame in the basic sense specified here. In this paper, I have only attempted to articulate a theory of what basically deserved blame is. I take it to be an open philosophical question whether anyone deserves it. I assume that if no one has free will, no one deserves to be blamed in this basic sense of desert. Nothing in the preceding discussion was intended to settle the freewill question. As a compatibilist, I do think that most people possess free will and that most of the time they act freely. However, I grant this is a contestable view. As result, so is the question of whether anyone deserves blame in a basic sense of desert. Nevertheless, one point I hope to have established has to do with what a blameworthy person would deserve if she did have free will, and what would be good about it. Some philosophers, such as Galen Strawson, have argued that the freedom at issue in the freewill debate is the type required to make intelligible deserved eternal suffering in hell. ${ }^{55}$ In my view, this helps to set the intuitive bar for the sort of freedom needed so high that it quickly becomes clear that nothing metaphysically possible for finite beings like us could hit that bar, which is exactly the conclusion Galen Strawson himself draws. But if the theory of deserved blame offered above is anywhere within the vicinity of correct, the freedom that would be needed to deserve blame would only help ground a culpable person's being subject to the limited interpersonal social harms identified here. That still might require a fairly robust freedom, but at least it seems to be within the reach of mere mortals like us. ${ }^{56}$

University of Arizona msmckenna@email.arizona.edu

\section{Strawson, “The Impossibility of Moral Responsibility."}

I have profited from two excellent sets of referee reports from the Journal of Ethics and Social Philosophy, as well as two excellent sets of referee reports from Ethics. I am grateful to each of these referees for their careful attention. I would like to thank Dana Nelkin, Derk Pereboom, Guido Pincione, Carolina Sartorio, and David Shoemaker for helpful written comments on an earlier draft of this paper. I presented earlier versions of this paper to the Philosophy Department at the University of Calgary in fall 2013, and in the summer of the same year to a workshop in Park City, Utah, sponsored by the University of Arizona Center for the Philosophy of Freedom. I also presented yet a further revised version at the Gothenburg Responsibility Conference in Gothenburg, Sweden, in August 2016. For helpful comments at the Calgary session, I would like to thank Justin Caouette, Randolph Clarke, Ishtiyaque Haji, Daniel Haas, Noa Latham, Mark Migotti, and Angela Smith. For helpful comments at the Park City session, I would like to thank Elijah Milgram, Carmen Pavel, Guido Pincione, Daniel Russell, David Schmidtz, and Steve Wall. For helpful comments at the Gothenburg session, I would like to thank Santiago Amaya, Joe Campbell, Randolph Clarke, Derk Pereboom, Ingmar Persson, Paul Russell, David Shoemaker, Saul Smilansky, Helen Steward, Matt Talbert, and Kadri Vihvelin. 


\section{REFERENCES}

Adams, Marilyn McCord. Horrendous Evils and the Goodness of God. Ithaca, NY: Cornell University Press, 1999.

Bennett, Christopher. "The Varieties of Retributive Experience." Philosophical Quarterly 52, no. 207 (April 2002): 145-63.

Chisholm, Roderick. "The Defeat of Good and Evil." Proceedings of the American Philosophical Association 42 (1968-69): 21-38.

Clarke, Randolph. "Some Theses on Desert." Philosophical Explorations 16, no. 2 (2013): 153-64.

Feinberg, Joel. Doing and Deserving: Essays in the Theory of Responsibility. Princeton: Princeton University Press, 1970.

- Harm to Others: The Moral Limits of the Criminal Law. New York: Oxford University Press, 1986.

Fischer, John Martin, and Mark Ravizza. Responsibility and Control: An Essay on Moral Responsibility. Cambridge: Cambridge University Press, 1998.

Hieronymi, Pamela. "The Force and Fairness of Blame." Philosophical Perspectives 18, no. 1 (December 2004): 115-48.

Korsgaard, Christine. “Two Distinctions in Goodness." Philosophical Review 92, no. 2 (April 1983): 169-95.

Lenman, James. "Compatibilism and Contractualism: The Possibility of Moral Responsibility." Ethics 117, no. 1 (October 2006): 7-31.

Macnamara, Coleen. "Reactive Attitudes as Communicative Entities." Philosophy and Phenomenological Research 90, no. 3 (May 2015): 546-69.

McKenna, Michael. Conversation and Responsibility. New York: Oxford University Press, 2012.

- "Directed Blame and Conversation." In Blame: Its Nature and Norms, edited by D. Justin Coates and Neal A. Tognazzini, 119-40. New York: Oxford University Press, 2013.

McNaughton, David. Moral Vision: An Introduction to Ethics. New York: Blackwell, 1988.

Mele, Alfred. Free Will and Luck. New York: Oxford University Press, 2006.

Moore, G. E. Principia Ethica. New York: Cambridge University Press, 1903.

Nelkin, Dana. "Moral Responsibility, Conversation, and Desert: Comments on Michael McKenna's Conversation and Responsibility." Philosophical Studies 171, no. 1 (October 2014): 63-72.

Pereboom, Derk. Free Will, Agency, and Meaning in Life. New York: Oxford University Press, 2014.

__. "Free Will Skepticism, Blame, and Obligation." In Blame: Its Nature and 
Norms, edited by D. Justin Coates and Neal A. Tognazzini, 189-206. New York: Oxford University Press, 2013.

- Living Without Free Will. Cambridge: Cambridge University Press, 2001. Rawls, John. A Theory of Justice. Cambridge, MA: Harvard University Press, 1971. Sartorio, Carolina. Causation and Free Will. Oxford: Oxford University Press, 2016.

Scanlon, T.M. "Giving Desert Its Due." Philosophical Explorations 16, no. 2 (2013): 101-16.

-Moral Dimensions: Permissibility, Meaning, Blame. Cambridge, MA: Belknap Press, 2008.

-What We Owe to Each Other. Cambridge, MA: Harvard University Press, 1998.

Smart, J.J. C. "Free-Will, Praise and Blame." Mind 70, no. 279 (July 1961): 291306.

Shoemaker, David. Responsibility from the Margins. Oxford: Oxford University Press, 2015.

Strawson, Galen. “The Impossibility of Moral Responsibility." Philosophical Studies 75, nos. 1/2 (August 1994): 5-24.

Strawson, Peter. "Freedom and Resentment." Proceedings of the British Academy 48 (1962): $1-25$.

Vargas, Manuel. Building Better Beings: A Theory of Moral Responsibility. New York: Oxford University Press, 2013.

Wallace, R. Jay. Responsibility and the Moral Sentiments. Cambridge, MA: Harvard University Press, 1994.

Watson, Gary. "Responsibility and the Limits of Evil: Variations on a Strawsonian Theme." In Responsibility, Character, and the Emotions: New Essays in Moral Psychology, edited by Ferdinand Schoeman, 256-86. Cambridge: Cambridge University Press, 1987. 